\title{
Changes in Subcellular Distribution of Ependymins in Goldfish Brain Induced by Learning
}

\author{
Rupert Schmidt \\ Department of Zoology, J. W. Goethe-University, Frankfurt, F.R.G.
}

\begin{abstract}
Goldfish were trained for $4 \mathrm{~h}$ to swim with an attached polystyrene foam float and tested for retention 3 days later. Intracerebroventricular injection of anti-ependymin antisera was shown to prevent long-term memory formation of this vestibulomotor learning task, as reported previously. In further experiments, fish were killed 4-14 h after the start of training. The brains were dissected, incubated in an isoosmolar solution for collection of proteins of the brain extracellular fluid (ECF), homogenized, and fractionated by differential centrifugation. The ECF, a supernatant fraction enriched in cytoplasmic constituents $\left(\mathrm{S}_{3}\right)$, and various particulate subcellular fractions were analyzed for their ependymin contents by radioimmunoassay. No statistically significant changes that might be induced by the learning were revealed in any of the particulate fractions. Steady-state concentrations of ependymins in the cytoplasm, however,
\end{abstract}

increased temporarily by $39 \%$ in fish that had mastered the training task as compared with nonlearning animals (passive and active controls). In the ECF, the specific concentration of ependymins first decreased to $88 \%$ of control levels (4-5 $\mathrm{h}$ after the start of training), but later on, it increased to $138 \%(8-14 \mathrm{~h})$. Apparently, ependymins present in the ECF are used during biochemical reactions of memory consolidation. The resulting decrease in extracellular ependymin concentrations might trigger their resynthesis in the cytoplasm and lead to an increased release of these glycoproteins into the ECF. Key Words: Memory and learningGoldfish brain proteins-Behavioral plasticity-CSFProtein synthesis-Extracellular glycoproteins. Schmidt R. Changes in subcellular distribution of ependymins in goldfish brain induced by learning. $J$. Neurochem. 48, 18701878 (1987).
Many investigations have demonstrated that memory consolidation can only proceed if protein biosynthesis is undisturbed (for review, see Rosenzweig and Bennett, 1976; Dunn, 1980; Agranoff, 1981; Rose, 1981; Shashoua, 1982; Shashoua and Schmidt, 1987). Most studies were done either by intracranial injection of protein synthesis inhibitors after the acquisition phase of a new behavior or by administration of radioactive amino acids as precursor molecules. So far, however, only a few proteins have been identified that increase in content after learning. One example is tubulin after passive avoidance learning in the chick (Mileusnic et al., 1980). Increased synthesis has also been claimed for S-100 and the neuronal enolase 143-2 in hippocampal pyramidal neurons of rat brain after handedness reversal and passive avoidance conditioning (Hydén and Lange, 1970a,b; Haglid et al., 1975; Rönnback and Hydén, 1980) and was measured by radioimmunoassay techniques in the cortex, brainstem, and medulla, but not in the cerebellum, of rats after a T-maze performance task (Zomzely-Neurath and Keller, 1977; for a critical review, see Zomzely-Neurath and Walker, 1980).

The synthesis of two goldfish glycoproteins, ependymins $\beta$ and $\gamma$, is specifically enhanced when the animals learn to swim with an attached float (Shashoua, 1976). After the fish were subjected to this vestibulomotor training task (Shashoua and Moore, 1978) and after classical conditioning in the shuttle-box (Schmidt and Piront, 1985), anti-ependymin antisera were injected into brain ventricles and found to prevent memory consolidation. By radioimmunoassay (Schmidt and Shashoua, 1981), ependymins were shown to be characteristic constituents in the CNS of untrained goldfish, enriched in the optic tectum, the tegmentum, and vagal lobes (Schmidt and Lapp, $1987 a$ ). Ependymin-like immunoreactivity was also encountered in other fish and in the rat hippocampus (Schmidt et al., 1986). After subcellular fractionation of the goldfish brain, relatively small amounts of epen-

Received August 15, 1986; revised December 2, 1986; accepted December 2, 1986.

Address correspondence and reprint requests to Dr. R. Schmidt at Zoologisches Institut, J. W. Goethe-Universität, Siesmayerstrasse 70, Postfach 111932, D-6000 Frankfurt am Main, F.R.G.

Abbreviations used: ANL, active nonlearner; ECF, extracellular fluid; $L$, learner; $N$, untrained (naive); PNL, passive nonlearner. 
dymins were recovered in fractions enriched in cell nuclei, mitochondria, synaptosomes, various membranes, myelin, or microsomes. Ependymins are mainly soluble cytoplasmic constituents (Schmidt and Lapp, 1987 b) but are secreted in cell cultures (Majocha et al., 1982) and also in situ (Schmidt and Lapp, 1987a), observations suggesting that injected anti-ependymin antisera might interfere with ependymin molecules within the extracellular fluid (ECF).

The enhanced incorporation (59-72\%) of radioactive valine into ependymins after float training (Shashoua, 1976) does not necessarily imply a higher steady-state concentration. It could equally well result from an accelerated turnover arising from the replenishment of ependymin pools that had been depleted during the training task. This is not unlikely, because ependymin $\beta$ is known to be proteolyzed to ependymin $\gamma$ and smaller peptides in the ECF (Schmidt and Shashoua, 1983). For determination of which is the case, changes in the steady-state concentrations of ependymins after the float training were analyzed quantitatively by radioimmunoassay. Special attention was paid to the functional importance of secretion of ependymins into the ECF during memory consolidation.

\section{MATERIALS AND METHODS}

\section{Behavioral experiments}

Goldfish (Carassius auratus) were kept in groups of 50 fish at $21^{\circ} \mathrm{C}$ in aerated $80-\mathrm{L}$ tanks in the animal house for at least 6 weeks before the experiments. Fish were trained to swim with an attached float (Shashoua, 1968). This paradigm imposes a difficult task on the animals, involving somatic and visceral afferences and motoric and vegetative reactions. It was designed to increase the chance of detecting biochemical changes after learning. Furthermore, it has the advantage of not involving any handling of the fish during the training session. The disadvantage is that the float training cannot easily be compared with the associative learning paradigms described in the psychologically oriented literature.

Although no seasonal variation in the behavior was observed with fish kept at a constant 12-h light/dark cycle, all experiments were performed between September and April, as goldfish have been reported to learn better during the winter season (Shashoua, 1973). One week before the training, groups of 10 fish were put into $15-\mathrm{L}$ training tanks. Because fish are known to orientate by gravity and phototaxis (see von Holst, 1970), the training tanks were illuminated from above, and the sides were almost completely shielded with black cardboard. The body weight, shape, and individual coloring of each fish were recorded. A numbered cylindrical float was prepared from polystyrene foam for each fish, with a diameter of $10.5 \mathrm{~mm}$, and a length, in $\mathrm{mm}$, equivalent to the fish's weight (in g) minus 1 (thus, a goldfish weighing $8.3 \mathrm{~g}$ received a float of $7.3 \mathrm{~mm}$ in length).

The fish were fed for the last time in the morning before training $10 \mathrm{~min}$ after the onset of the light period in the animal house, and experiments were begun $50 \mathrm{~min}$ later. The floats were sutured at the fishes' ventral midline, $2 \mathrm{~mm}$ caudal to the base of their pectoral fins. The fish were then re- turned to the training tanks, and their performance was scored according to the criteria recommended by Shashoua (1973). With a range of $0-100 \%$ achievement of the vestibulomotoric task, these criteria offer a reproducible scale with an average accuracy of $6.6 \pm 1.6 \%$ with different observers. The first behavioral score was assigned $10 \mathrm{~min}$ after attachment of the float, because many fish exhibit unspecific escape behavior during the first $5 \mathrm{~min}$, which is not related to their ability to adjust to the float. Thereafter, each fish was observed every $30 \mathrm{~min}$ for $30 \mathrm{~s}$. Four hours later, the floats were removed, and fish were classified according to the improvement in their swimming performance. Those fish that had improved their performance by $\geq 40 \%$ were assigned to group L; those fish displaying changes of $\leq 15 \%$ were assigned to group PNL if their score at the beginning of training was $\leq 10 \%$, but they were assigned to group ANL if it was $\geq 50 \%$. In the literature, these groups have been classified, respectively, as learners, passive nonlearners, and active nonlearners (Shashoua, 1976). It should be kept in mind, however, that "learning" in this context is an operational description for an observed behavioral change, which does not necessarily imply the same mechanisms as associative learning. To avoid confusion, therefore, we will use the nonjudgmental descriptions L, PNL, and ANL and defer any interpretation to Discussion. In pilot experiments, fish not falling into the defined groups were also analyzed biochemically, and they gave results intermediate (and more variable) between those reported here for L and PNL. These data were not included in the final evaluation.

Immediately after removal of the floats, the fish were returned to their 80-L home tanks (not to the training tanks) so that the stress exerted by the training environment, which may interfere with long-term memory formation (for a detailed discussion of this problem, see Davis and Agranoff, 1966; Agranoff et al., 1978), was reduced.

\section{Injection of anti-ependymin antisera}

Antisera against the immunogens ependymin $\beta$, ependymin $\gamma$, or a mixture of both proteins were raised in rabbits. All new antisera obtained react almost identically with ependymins $\beta$ and $\gamma$ in the radioimmunoassay, irrespective of the ependymin used as immunogen, as reported earlier for other anti-ependymin antisera raised in Shashoua's laboratory (compare Schmidt and Shashoua, 1983). The avidities of the antibody-antigen complexes, as determined by Scatchard plot analyses, were also similar, but the antiserum raised against the mixture of both immunogens had a threefold higher titer. Only in immunohistofluorescence experiments with the embryonic hippocampus of the rat did they exhibit slightly different staining characteristics (Schmidt et al., 1986), which are possibly caused by differences in the native conformations of the $\beta$ and $\gamma$ proteins. Anti-ependymin antisera do not cross-react with other goldfish brain proteins. For control purposes, the specific anti-ependymin antibodies were removed from the antisera by incubation with the antigen (for details, see Schmidt and Shashoua, 1983). Preimmune sera from the same rabbits were used as further controls.

A small hole was drilled into the skull of the goldfish (see Schmidt and Lapp, 1987a), and $10 \mu$ lof antiserum was injected into the fourth brain ventricle 8 and $24 \mathrm{~h}$ after the beginning of the float training. This procedure was shown in preliminary experiments to give more reproducible results than single injections of the antiserum. These experiments were performed so that we could clearly establish whether 
the new antisera used in our biochemical analyses recognize the same proteins and have the same influence on the behavior as those used by Shashoua and Moore (1978). The experiments were performed double-blind, i.e., the person injecting the serum did not know whether antiserum or preimmune serum was being injected and the observer testing the animals did not know with which serum the fish had been injected.

\section{Biochemical methods}

At various intervals after training, the fish were anesthetized by cooling in ice water for $10 \mathrm{~min}$ and decapitated. All materials and methods used for subcellular fractionation and quantification of marker enzymes, total protein, and ependymins were exactly as described by Schmidt and Lapp $(1987 b)$. In brief, five brains, from either L, PNL, ANL, or untrained [naive $(\mathrm{N})$ ] fish, were pooled, extracted in isoosmolar phosphate-buffered saline containing protease inhibitors, homogenized, and separated by differential centrifugation to obtain the following fractions: ECF; homogenate; a nuclear pellet fraction, $\mathrm{P}_{1}$; a crude synaptosomal fraction, $\mathrm{P}_{2}$; a microsomal fraction, $\mathrm{P}_{3}$; and a cytoplasmic high-speed supernatant fraction, $S_{3}$. The contribution of subcellular organelles to these fractions was monitored by means of characteristic marker substances and fine structural analysis (Schmidt and Lapp, 1987b). The total protein content in the fractions was determined using a modified Lowry procedure. Ependymins $\beta$ and $\gamma$ were quantified using a specific radioimmunoassay that is equally sensitive to both proteins (Schmidt and Shashoua, 1981).

Relative ependymin concentrations in goldfish brain (as a percentage of the total protein content) are neither a function of the fishes' age nor of the season of the year (Schmidt and Shashoua, 1981). The extractability of goldfish brain or the distribution of subcellular particles, however, may change with the age of the experimental animals and may cause artifacts. Special care was taken, therefore, to assign only fishes of matched body weight $( \pm 0.2 \mathrm{~g})$ to the groups compared in the biochemical analyses.

The fish were coded before extraction and homogenization, so that the person performing the subcellular fractionation and the analytical determinations did not know which groups of fish were L, PNL, ANL, or N. Only after completion of all determinations and calculations was the code broken. Mean values are given with their SEM (from $n$ experiments). Significant differences were established using a twotailed $t$ test with corrections for unequal variances.

\section{RESULTS}

\section{Effect of anti-ependymin antisera on memory consolidation}

Altogether, 1,220 goldfish were trained to swim with the float. Of these, $21 \%$ were classified as $\mathrm{L}, 44 \%$ as PNL, and $6 \%$ as ANL (Fig. 1). Twenty-nine percent displayed an improvement during the training that was intermediate between $\mathrm{L}$ and PNL, and they were not included in the final evaluation. Five fish had to be killed after intracerebroventricular injection, because they displayed signs of vestibular injury.

The inhibitory effect of anti-ependymin antisera on the retention of the task is summarized in Table 1. Memory consolidation was blocked to the same ex-

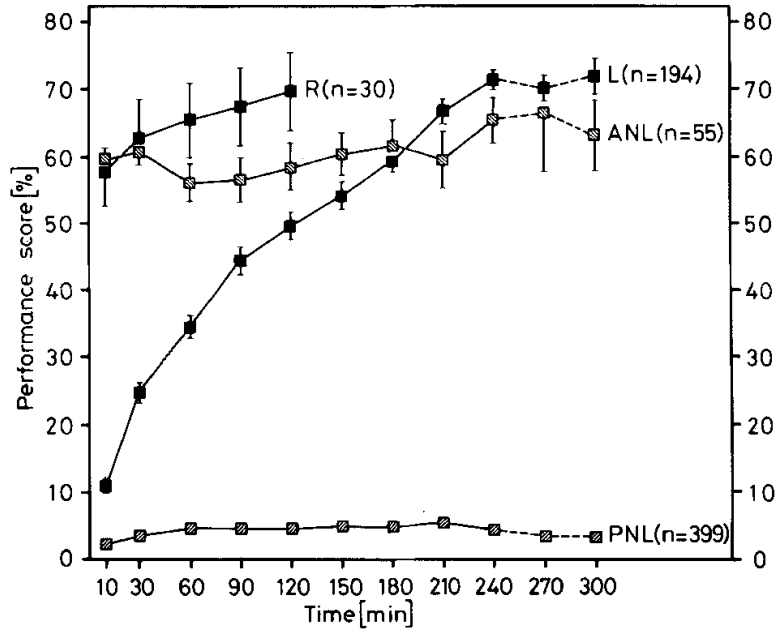

FIG. 1. Training goldfish to swim with an attached polystyrene float. Six hundred forty-eight fish were trained and classified as $\mathrm{L}$, PNL, or ANL. Twenty $\mathrm{L}$ and $10 \mathrm{ANL}$ fish were trained for $5 \mathrm{~h}$, instead of the standard procedure of $4 \mathrm{~h}$, but they did not further improve in their performance scores. Thirty $L$ fish were tested 3 days later for their ability to recall the task $(R)$.

tent by antisera raised against ependymin $\beta$ or $\gamma$. This had been anticipated, as both antisera react with the same antigenic determinants (see Materials and Methods). On average, goldfish injected with antiependymin antisera achieved retention scores of only $18 \%$. Four types of controls were used (Table 1). (a) Some fish were tested for retention without injection of serum. Others were tested after injection of (b) preimmune serum from the same rabbits or (c) an antiserum from which the specific anti-ependymin antibodies had been removed. (d) A fourth group of goldfish was trained (day 1) and tested for retention (day 4). They were then injected with anti-ependymin antiserum on day $6,1 \mathrm{~h}$ before a second test session. This control was designed to prove that the antisera do not interfere with the behavior once consolidated or with the ability to swim with the float as such. Retention scores for the control groups varied between $56 \%$ (d) and $91 \%$ (a). The differences between fishes injected with antisera and controls were highly significant ( $p$ $<0.001$ ). In two experiments, fish of groups PNL and ANL were injected with antisera. The retention score of group ANL was $105 \pm 17 \%$, and group PNL had to be classified again as PNL in the test session.

\section{Changes in concentrations of ependymins induced by training}

The same anti-ependymin antisera were applied in the behavioral experiments and in the radioimmunoassay measurements. Five fish brains were pooled for each determination so that errors resulting from random differences among individual animals were minimized. In a first set of experiments, the time when the fish were killed was not well defined, ranging from 5 to $8 \mathrm{~h}$ after the start of training. The total brain con- 
TABLE 1. Effect of injected anti-ependymin antisera on memory consolidation

\begin{tabular}{|c|c|c|c|c|c|}
\hline \multirow[b]{2}{*}{ Injection of } & \multirow[b]{2}{*}{$\mathbf{n}$} & \multicolumn{2}{|c|}{ Day 1: training } & \multicolumn{2}{|c|}{ Day 4: test } \\
\hline & & $\begin{array}{l}\text { Improvement of } \\
\text { behavior by } \\
\text { training }\end{array}$ & $\begin{array}{l}\text { Score at the end } \\
\text { of training }\end{array}$ & $\begin{array}{l}\text { Score at } 20 \mathrm{~min} \\
\text { of testing }\end{array}$ & $\begin{array}{l}\text { Retention as \% of } \\
\text { training score }\end{array}$ \\
\hline Anti-ependymin $\beta$ & 20 & $60 \pm 5$ & $64 \pm 6$ & $14 \pm 4$ & $22 \pm 8$ \\
\hline Anti-ependymin $\gamma$ & 20 & $57 \pm 5$ & $73 \pm 5$ & $14 \pm 4$ & $19 \pm 5$ \\
\hline Anti-ependymin $(\beta+\gamma)$ & 6 & $43 \pm 5$ & $45 \pm 7$ & $0 \pm 0$ & $0 \pm 0$ \\
\hline All experimentals & 46 & $55 \pm 3$ & $66 \pm 3$ & $12 \pm 3$ & $18 \pm 5$ \\
\hline No injection & 34 & $48 \pm 3$ & $67 \pm 3$ & $60 \pm 4$ & $91 \pm 6$ \\
\hline Preimmune serum & 25 & $52 \pm 4$ & $72 \pm 4$ & $50 \pm 6$ & $69 \pm 8$ \\
\hline Preabsorbed serum & 14 & $47 \pm 5$ & $60 \pm 3$ & $43 \pm 4$ & $72 \pm 9$ \\
\hline Anti-ependymin ${ }^{a}$ & 15 & $62 \pm 7$ & $82 \pm 5$ & $45 \pm 7$ & $56 \pm 7$ \\
\hline All controls & 88 & $51 \pm 2$ & $70 \pm 2$ & $53 \pm 3$ & $75 \pm 4$ \\
\hline
\end{tabular}

Fish were trained to swim with a polystyrene float for $4 \mathrm{~h}$ on day 1 . The floats were then removed. Group $\mathrm{L}$ fish were injected with antiserum directed against ependymin $\beta, \gamma$, or a mixture of both immunogens ( $\beta$ and $\gamma$ ) or preimmune or preabsorbed serum at 8 and 24 h after the beginning of the training and tested for retention 3 days later. The retention score at 20 min of testing on day 4 is expressed as a percentage of the final performance score during training (last column). All antisera recognize the same antigenic determinants, but the antiserum raised against the mixture of $\beta$ and $\gamma$ had the highest titer. Mean values are from $n$ tested animals. All differences between experimental and control groups were highly significant $(p<0.001)$.

${ }^{a}$ As a control, fish were trained on day 1 and tested for recall on day 4 . Group $L$ fish were then injected with anti-ependymin antiserum $1 \mathrm{~h}$ before a second test session on day 6 . For this group, the retention at 20 min of testing on day 6 is expressed as a percentage of the final score on day 4.

tents of ependymins increased by $20 \%$ as compared with the untrained $(\mathrm{N})$ control fish (Table 2). The brains were then extracted to obtain extracellular constituents, homogenized, and fractionated by ultracentrifugation. The only pronounced change in the steady-state concentration of ependymins was found in the high-speed cytoplasmic supernatant fraction $\mathrm{S}_{3}$ (Table 2). The ependymin content in this fraction increased by $39 \%(p=0.1)$. No change rising above the experimental variance was noticed in any of the particulate fractions $\left(\mathrm{P}_{1}\right.$, nuclear; $\mathrm{P}_{2}$, synaptosomal; or

TABLE 2. Changes in ependymin concentrations after float training

\begin{tabular}{lccr}
\hline $\begin{array}{l}\text { Subcellular } \\
\text { fraction }\end{array}$ & $\begin{array}{c}\text { Group N } \\
\text { ( } \mu \text { g of ependymins/g wet weight) }\end{array}$ & $\begin{array}{c}\text { Group L } \\
(\%)\end{array}$ \\
\hline Total brain & $1,945 \pm 137(45)$ & $2,334 \pm 376(18)$ & 20.0 \\
ECF & $539 \pm 34(25)$ & $489 \pm 77(16)$ & -9.3 \\
$\mathrm{P}_{1}$ & $178 \pm 45(24)$ & $193 \pm 60(15)$ & 8.4 \\
$\mathrm{P}_{2}$ & $88 \pm 16(23)$ & $101 \pm 24(15)$ & 14.8 \\
$\mathrm{P}_{3}$ & $53 \pm 17(25)$ & $60 \pm 21(15)$ & 13.2 \\
$\mathrm{~S}_{3}$ & $1,062 \pm 102(26)$ & $1,481 \pm 296(15)$ & 39.4 \\
\hline
\end{tabular}

Goldfish were trained for $4 \mathrm{~h}$ to swim with an attached float. Fish that had mastered the adjustment to the float training were killed 1-4 h later (group L). Brains were extracted to collect ECF (five brains per sample), homogenized, and separated by differential centrifugation to isolate the following fractions: $P_{1}$ (nuclear), $1,000 g_{a v}$ for $10 \mathrm{~min} ; P_{2}$ (crude synaptosomal), $17,000 g_{\mathrm{av}}$ for $60 \mathrm{~min} ; \mathrm{P}_{3}$ (microsomal), $170,000 g_{a v}$ for $105 \mathrm{~min}$; and $\mathrm{S}_{3}$ (cytoplasmic). Ependymin concentrations are compared with those of untrained controls (group $\mathrm{N}$ ). Data are mean \pm SEM values (no. of experiments).
$\mathrm{P}_{3}$, microsomal). In the ECF, a tendency toward lower concentrations after training was noticed $(-9 \%$; Table 2 ). Because the variance of the trained animals was much larger than that of the controls, it was decided to study the time course of ependymin concentrations after training and to concentrate on the fraction exhibiting the largest change $\left(\mathrm{S}_{3}\right)$.

\section{Time course of increased ependymin levels after training}

Changes in the concentrations of ependymins in the ECF and the cytoplasmic fraction $\mathrm{S}_{3}$ were analyzed at various times after the start of training. Twenty-five $L$ (five groups of five fish each) were compared with 25 PNL at each interval. In addition, 85 (17 times 5) untrained goldfish and $40 \mathrm{ANL}$ were used as controls (Tables 3 and 4). Only ECF and the cytoplasmic fraction $S_{3}$ were prepared in these experiments so that preparation was speeded up and unreproducible loss of ependymins by proteolytic activities was minimized.

The ependymin content in the cytoplasm rose from 1,089 to $1,455 \mu \mathrm{g} / \mathrm{g}$ of brain tissue (by $33.6 \% ; \mathrm{p}$ $<0.02$ ) within $4-5 \mathrm{~h}$ from the start of the float training (Table 3). It can be seen from Table 3 that the increase in steady-state concentrations of ependymins cannot be explained by an acceleration in the overall rate of protein biosynthesis, because the total protein content in the cytoplasmic fraction remained constant. The specific ependymin concentration reached a maximum at $\sim 5.5 \mathrm{~h}$ ( $7.6 \%$ of the protein), remained high for $\sim 4 \mathrm{~h}$, and then returned to control levels within 
TABLE 3. Changes in ependymin concentrations in cytoplasm

\begin{tabular}{|c|c|c|c|c|c|c|c|c|}
\hline \multirow[b]{2}{*}{ Group } & \multirow[b]{2}{*}{ Time (h) } & \multirow[b]{2}{*}{$\mathbf{n}$} & \multicolumn{2}{|c|}{ Ependymins } & \multicolumn{2}{|l|}{ Protein } & \multicolumn{2}{|c|}{ Ependymins/protein } \\
\hline & & & $\mu \mathrm{g} / \mathrm{g}$ wet weight & $\mathbf{p}$ & $\mathrm{mg} / \mathrm{g}$ wet weight & p & $\%(w t / w t)$ & $\mathrm{p}$ \\
\hline $\mathrm{N}$ & & 17 & $1,089 \pm 59$ & - & $19.7 \pm 0.7$ & 一 & $5.5 \pm 0.3$ & - \\
\hline $\begin{array}{l}\text { L } \\
\text { L } \\
\text { L } \\
\text { L }\end{array}$ & $\begin{array}{l}4-5 \\
5-6 \\
6-8 \\
8-10\end{array}$ & $\begin{array}{l}5 \\
5 \\
5 \\
5\end{array}$ & $\begin{array}{r}1,455 \pm 187 \\
1,502 \pm 233 \\
1,430 \pm 267 \\
980 \pm 195\end{array}$ & $\begin{array}{c}<0.02 \\
<0.02 \\
<0.1 \\
-\end{array}$ & $\begin{array}{l}20.1 \pm 0.7 \\
19.9 \pm 0.6 \\
20.1 \pm 2.0 \\
18.7 \pm 2.5\end{array}$ & $\begin{array}{l}- \\
-\end{array}$ & $\begin{array}{l}7.2 \pm 0.8 \\
7.6 \pm 1.2 \\
6.8 \pm 0.9 \\
5.2 \pm 0.7\end{array}$ & $\begin{array}{l}<0.01 \\
<0.02 \\
<0.1 \\
-\end{array}$ \\
\hline $\mathrm{L}$ & $4-10$ & 20 & $1,342 \pm 113$ & $<0.1$ & $19.7 \pm 0.8$ & - & $6.7 \pm 0.5$ & $<0.05$ \\
\hline $\begin{array}{l}\text { PNL } \\
\text { PNL } \\
\text { PNL } \\
\text { PNL }\end{array}$ & $\begin{array}{l}4-5 \\
5-6 \\
6-8 \\
8-10\end{array}$ & $\begin{array}{l}5 \\
5 \\
5 \\
5\end{array}$ & $\begin{array}{r}1,011 \pm 91 \\
1,188 \pm 194 \\
1,063 \pm 113 \\
932 \pm 169\end{array}$ & $\begin{array}{l}\overline{-} \\
\overline{-}\end{array}$ & $\begin{array}{l}18.5 \pm 0.9 \\
21.6 \pm 0.9 \\
21.7 \pm 2.0 \\
16.5 \pm 1.8\end{array}$ & $\begin{array}{l}- \\
- \\
-\end{array}$ & $\begin{array}{l}5.6 \pm 0.7 \\
5.5 \pm 0.8 \\
5.0 \pm 0.4 \\
5.5 \pm 0.6\end{array}$ & $\begin{array}{l}- \\
- \\
-\end{array}$ \\
\hline PNL & $4-10$ & 20 & $1,049 \pm 71$ & - & $19.6 \pm 0.8$ & - & $5.4 \pm 0.3$ & - \\
\hline ANL & $4-10$ & 8 & $1,287 \pm 162$ & - & $21.7 \pm 1.8$ & - & $5.8 \pm 0.3$ & - \\
\hline
\end{tabular}

Goldfish were trained for $\mathbf{4} \mathrm{h}$ to swim with a float and killed at various times after the beginning of the experiment. The absolute $(\mu \mathrm{g} / \mathrm{g}$ wet weight) as well as the specific (as percentage of total protein) ependymin concentrations in the cytoplasmic fraction $\mathrm{S}_{3}$ of group $L$ fish increased significantly over those of untrained control animals $(\mathrm{N})$. Ependymin concentrations of groups PNL and ANL did not differ from those of controls $(\mathrm{N})$. Three hundred twenty-five goldfish were used in this experiment, and brains were analyzed in groups, each pooled from five brains. Data are mean \pm SEM values from $n$ groups.

$10 \mathrm{~h}$ from the beginning of the experiment (Fig. 2). No significant changes were observed either in the cytoplasmic fraction of PNL fish killed after the same intervals as $\mathrm{L}$ or in ANL fish.

In the ECF, ependymin concentrations decreased, although not significantly, during the first $2 \mathrm{~h}$ after removal of the floats, from 546 to $505 \mu \mathrm{g} / \mathrm{g}$ of brain tissue (Table 4). At longer intervals after acquisition of the task, however, ependymin concentrations increased notably (by $33.7 \% ; \mathrm{p}<0.005$; Table 4 ). As for the cytoplasmic fraction, the increase cannot be explained by a general enhancement of the protein turnover, but rather results from changes specific to ependymins. The higher relative ependymin concentration still persisted at $14 \mathrm{~h}$ after the start of training (Fig. 3). Both PNL and ANL did not differ in their ependymin contents in the ECF as compared with untrained controls.

\section{DISCUSSION}

Although the importance of undisturbed protein biosynthesis for long-term memory formation has been clearly demonstrated, the search for changes in the concentrations of defined proteins has frequently been compared with looking for a needle in a haystack. The analysis is hampered by four factors: (a) Only a few distinct proteins can be quantified. (b) Learning has been considered a minor event in an animal's life as compared with their other activities, such as feeding, fighting, breeding, and the like. It has been argued, therefore, that changes in protein concentra- tions after learning will be small. (c) The complex morphological diversity of the brain might restrict the changes to limited populations of cells, particular subcellular organelles, or both. (d) The enthusiastic search, in earlier decades, for specific polypeptides that were believed to contain the learned information in a coded form (similar to the ribonucleic acids) did

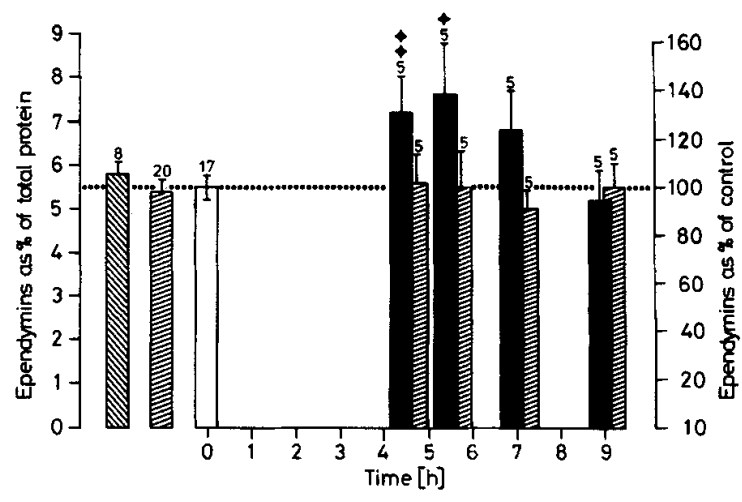

FIG. 2. Increase in specific ependymin concentration in goldfish brain cytoplasm after float training. Goldfish, classified according to their adopted swimming skill as $\mathrm{L}$ (solid columns) or PNL or ANL (cross-hatched columins), are compared with group $N$ fish (open column). Five groups of five brains each from $L$ fish and the same number of brains from PNL fish were pooled at each of the four intervals. They were extracted to collect the ECF (compare Fig. 3), homogenized, and centrifuged for separation of a cytoplasmic supernatant fraction, $S_{3}$. The specific ependymin concentration in this fraction was significantly higher between 4 and $6 \mathrm{~h}$ in group $\mathrm{L}$ relative to all other groups (" $\mathrm{p}<0.01, " \mathrm{p}<0.02$ ). Data are mean \pm SEM (bars) from $n$ independent samples. 
TABLE 4. Changes in ependymin concentrations in ECF

\begin{tabular}{|c|c|c|c|c|c|c|c|c|}
\hline \multirow[b]{2}{*}{ Group } & \multirow[b]{2}{*}{ Time (h) } & \multirow[b]{2}{*}{$\mathrm{n}$} & \multicolumn{2}{|c|}{ Ependymins } & \multicolumn{2}{|l|}{ Protein } & \multicolumn{2}{|c|}{ Ependymins/protein } \\
\hline & & & $\mu \mathrm{g} / \mathrm{g}$ wet weight & $\mathbf{p}$ & $\mathrm{mg} / \mathrm{g}$ wet weight & $\mathbf{p}$ & $\%(w t / w t)$ & $\mathrm{p}$ \\
\hline $\mathrm{N}$ & & 20 & $546 \pm 20$ & & $3.4 \pm 0.1$ & & $16.2 \pm 0.8$ & - \\
\hline L & $4-5$ & 5 & $507 \pm 40$ & - & $3.6 \pm 0.3$ & - & $14.4 \pm 1.0$ & - \\
\hline $\mathrm{L}$ & $5-6$ & 5 & $504 \pm 18$ & - & $3.1 \pm 0.1$ & - & $16.5 \pm 0.7$ & - \\
\hline $\mathrm{L}$ & $6-8$ & 5 & $625 \pm 109$ & - & $3.6 \pm 0.5$ & - & $17.5 \pm 1.6$ & - \\
\hline $\mathrm{L}$ & $8-10$ & 5 & $638 \pm 32$ & $<0.02$ & $3.0 \pm 0.2$ & - & $22.3 \pm 1.4$ & $<0.005$ \\
\hline $\mathrm{L}$ & $10-14$ & 3 & $730 \pm 38$ & $<0.005$ & $3.7 \pm 0.2$ & - & $19.8 \pm 0.3$ & $<0.001$ \\
\hline $\mathrm{L}$ & $4-14$ & 23 & $594 \pm 30$ & - & $3.3 \pm 0.1$ & - & $18.0 \pm 0.8$ & - \\
\hline PNL & $4-5$ & 5 & $649 \pm 166$ & - & $3.7 \pm 0.3$ & - & $16.6 \pm 3.0$ & - \\
\hline PNL & $5-6$ & 5 & $593 \pm 53$ & - & $3.3 \pm 0.2$ & - & $17.8 \pm 1.5$ & - \\
\hline PNL & $6-8$ & 5 & $649 \pm 88$ & - & $3.8 \pm 0.4$ & - & $16.9 \pm 1.4$ & - \\
\hline PNL & $8-14$ & 5 & $651 \pm 183$ & - & $4.2 \pm 1.2$ & - & $16.1 \pm 3.6$ & - \\
\hline PNL & $10-14$ & 2 & $669 \pm 8$ & - & $4.3 \pm 0.4$ & - & $15.6 \pm 0.4$ & - \\
\hline PNL & $4-14$ & 22 & $639 \pm 56$ & - & $3.8 \pm 0.3$ & - & $16.9 \pm 1.1$ & - \\
\hline ANL & $4-14$ & 8 & $581 \pm 24$ & - & $3.4 \pm 0.2$ & - & $17.5 \pm 1.4$ & 一 \\
\hline
\end{tabular}

Goldish were killed at the indicated times after the start of training and extracted to collect ECF proteins. The absolute and relative concentrations of ependymins in the ECF of group $\mathrm{L}$ first decreased and then increased significantly as compared with untrained controls $(\mathrm{N})$. Ependymin concentrations in groups PNL and ANL did not differ from those of controls. Three hundred sixty-five fish were used in this experiment and analyzed in groups, each pooled from five brains. Data are mean \pm SEM values from $n$ experiments.

not lead to conclusive results. On the other hand, (a) radioimmunoassays offer the means for measurement of even small differences in low concentrations. (b) Alterations in the amount of regulative biochemical factors during learning events might be as important as the adjustment of glucose levels after feeding, to name but one example. (c) The anatomical organization of the CNS may provide the necessary specificity for the manifestation of plastic changes, whereas (d) chemical signals, such as extracellular polypeptides, might act on synaptic membranes as a message "to whom it may concern" to consolidate exactly those neural circuits that had been "primed" by the preceding activity during the acquisition phase of the new behavior.

Ependymins have been proposed (Shashoua, 1982) as candidates for such tasks: They are specific to the nervous system and display a very rapid turnover (Schmidt and Lapp, 1987a). They are secreted into the ECF (Majocha et al., 1982; Schmidt and Lapp, $1987 \mathrm{~b}$ ), and ependymin-like immunoreactivity has also been demonstrated in pyramidal neurons of the mammalian hippocampus (Schmidt et al., 1986) and other structures of the limbic system (Shashoua, 1985). There is also some preliminary evidence that ependymins are taken up by subcellular organelles recovered in the crude synaptosomal fraction (Schmidt and Lapp, 1987b).

The increased synthesis of ependymins was first demonstrated in a cytoplasmic fraction $1-4 \mathrm{~h}$ after the float training by radioactive double-labeling, i.e., experimental animals were injected with $\left[{ }^{3} \mathrm{H}\right]$ valine, whereas controls were injected with $\left[{ }^{14} \mathrm{C}\right]$ valine. Ependymin molecules were identified by their enhanced ${ }^{3} \mathrm{H} /{ }^{14} \mathrm{C}$ ratio on electrophoresis gels (Shashoua, 1976). Subsequently, enhanced incorporation of radioactive precursor molecules was also shown in

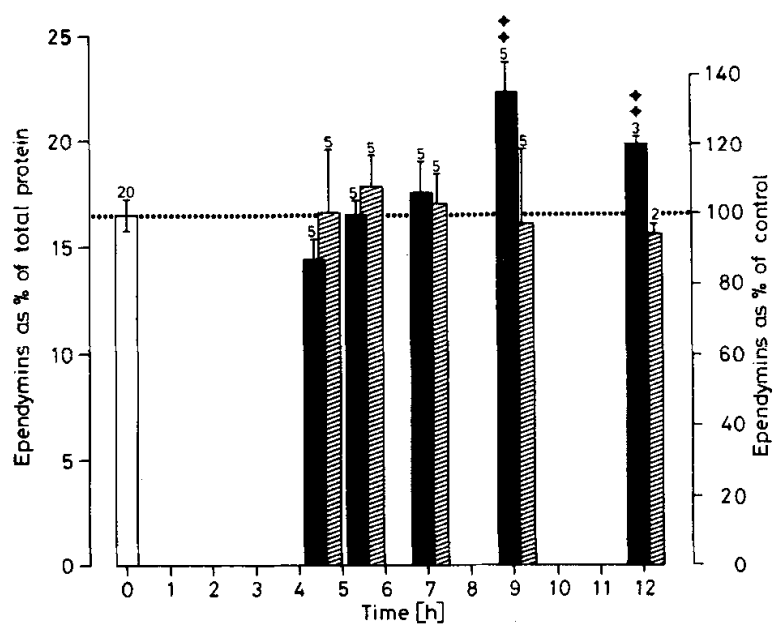

FIG. 3. Time course of ependymin concentrations in ECF after float training. The specific ependymin concentrations in the ECF of group $L$ (solid columns) were determined at various times after the start of training and compared with those of groups PNL (cross-hatched columns) and $\mathrm{N}$ (open column). The ependymin contents decreased first, before they increased significantly over control values $(" p<0.005)$. Data are mean \pm SEM (bars) values from $n$ independent samples. 
proteins of the ECF that migrated with the same electrophoretic mobilities as ependymins and exhibited similar immunodiffusion properties (Shashoua, 1979). These experiments cannot, however, differentiate between increased synthesis and turnover and do not allow any conclusion about quantitative changes of the actual steady-state concentrations.

Ependymin concentrations in various subcellular fractions were now measured by means of a specific radioimmunoassay. The antisera used in the assay had been prepared independently from those used in the behavioral experiments of Shashoua and Moore (1978), although by the same procedure (described by Schmidt and Shashoua, 1981). Intracerebroventricular injections of the new antisera after the float training produced the same amnestic effect, and the earlier observation (Shashoua and Moore, 1978) was confirmed that antisera are without influence, once consolidation of the new swimming skill has occurred. Anti-ependymin- $\gamma$ antiserum was as potent as anti- $\beta$ (Table 1), as anticipated from the metabolic relationship between these proteins. The new antisera also cause amnesia of an associative learning task, the classical conditioning in the shuttle-box (Schmidt and Piront, 1985; Schmidt, 1986).

Ependymin concentrations in a cytoplasmic fraction derived from goldfish that had mastered the adjustment to the float training (group L) were high compared with those of fish that did not improve their performance (groups N, PNL, and ANL). A trivial explanation would be that goldfish belong to two different groups, one with high anabolic capacity, capable of coping with the float, and the other characterized by weak protein biosynthesis and unable to swim under difficult conditions. If this were true, the float training would work as a test to select the "fit." The explanation is false, however, for four reasons: First, the increase was specific to ependymins, whereas the general protein content was unchanged (Table 3 ). Second, ependymin concentrations of PNL fish were equal to those of group N. Third, the ANL fish swam well, in spite of a low ependymin concentration (Table 3). Fourth, the increase in level of cytoplasmic ependymins of group $L$ was time dependent. Qualitatively similar results have been obtained for the increased incorporation of radioactive valine into ependymins (Shashoua, 1976). The time courses were also identical for the incorporation of valine, ependymin concentrations in the cytoplasm (this study), and changes in the synthesis of mRNA after the float training (Shashoua, 1974).

The increase in the specific concentration of ependymins in fraction $\mathrm{S}_{3}$ (38\%; Table 3), however, did not correspond quantitatively to the enhancement of valine incorporation (59-72\%; Shashoua, 1976), and no quantitative correlation was obtained between the increase in ependymin concentrations and the degree of learning (R. Schmidt, unpublished data). This raises the crucial question, inherent in all correlative studies on memory, whether the changes observed are functional for memory consolidation or concomitants of the animals' activity during training (Rose, 1981). The mechanical work done during the float swimming behavior by ANL fish, however, is presumably larger compared with that of $\mathrm{L}$ fish. Thus, the amount of work can hardly be responsible for the observed changes. Still, ependymin concentrations might be indicative of some other correlate of training, such as stress, to mention but one example. Nevertheless, the interference of anti-ependymin antisera with memory consolidation after the float training and the shuttlebox training (Schmidt and Piront, 1985; Schmidt, 1986) proves that the biochemical change is, at least, not an incidental one, but a necessary one (as, e.g., recovery from stress might well be).

The results reported here do not imply that the biochemical changes observed are specific to ependymins. The concentrations of many distinct proteins may change after learning (compare, e.g., tubulin; Mileusnic et al., 1980), and ependymins are but one class of characteristic constituents of the CNS that can be measured quantitatively. Second, the results do not imply that ependymins serve only the specific function of consolidating long-term memory, but they seem to be involved in one of the biochemical reactions that have to proceed after learning. Certainly, the same molecules may also participate in other reactions in the CNS.

In the cytoplasm, the rate of synthesis increased more than the steady-state concentration (see above), an observation suggesting that ependymins are used and metabolized during learning. The notion is favored by the observation that ependymins are secreted and proteolyzed. In the ECF, the ependymin concentration even decreased before it rose above control levels. One possible explanation is that the ECF and CSF serve as drainage devices for clearing the CNS of metabolites that have completed their physiological function. The inhibitory effect of the antisera administered into the brain ventricles, on the other hand, might indicate that ependymins exert their action from the ECF.

Only recently has the ECF been recognized as an important compartment of the nervous system. Extracellular glycoproteins and peptide factors, such as nerve growth factor and the ciliary neuronotrophic factor, regulate cellular survival, growth, intercellular adhesion, and differentiation (for references, see Harper and Thoenen, 1980; Varon and Adler, 1981; Unsicker, 1986). The protein concentration of goldfish ECF is almost as high as that of soluble cytoplasm (Shashoua, 1981), and ependymins are obviously major constituents of this compartment (Schmidt and Lapp, 1987a). Possibly the temporary decrease in level of extracellular ependymins after the acquisition is caused by their interaction with neuronal mem- 
branes, although we did not succeed in obtaining direct evidence for incorporation of ependymins into membranes or organelles recovered in the crude synaptosomal fraction (see also Schmidt and Lapp, $1987 \mathrm{~b}$ ). The decreased extracellular concentration might serve as a signal indicating a demand for these glycoproteins, which then, in turn, activates their synthesis. The approach of molecular genetics will help in determining whether the increased expression of ependymins after learning results from an enhanced efficiency in the transcription, translation, and/or stabilization of a previously translated message.

The biochemical reactions of ependymins are still open to speculation. The observations, made independently, that ependymins bind $\mathrm{Ca}^{2+}$ (Schmidt, $1985,1986)$ and that they aggregate in the absence of calcium (Shashoua, 1985) might give a clue as to their mode of action. By means of ion-selective electrodes, the extracellular calcium concentration has been found to decrease in cortical areas exposed to the cooperative interaction between specific and modulatory input systems during adaptive changes (Singer, 1987). Similarly, Krnjević et al. (1982) have reported a fall in extracellular calcium concentrations in the pyramidal cell layer after fimbrial-commissural stimulation of the rat hippocampus. Such alterations in extracellular calcium concentrations might influence the binding properties and the distribution of ependymins, possibly guiding their interaction with cell membranes.

Acknowledgment: The author thanks U. Johann and K.-P. Pfeifer for valuable assistance, A Polotzek for typing the manuscript, K. Grommet and H. Heidt for help with the graphic and photographic work, and the Deutsche Forschungsgemeinschaft for supporting grants (Schm 478/3 and 478/4).

\section{REFERENCES}

Agranoff B. W. (1981) Learning and memory: biochemical approaches, in Basic Neurochemistry, 3rd ed. (Siegel G. J., Albers R. W., Agranoff B. W., and Katzman R., eds), pp. 801-820. Little, Brown and Co., Boston.

Agranoff B. W., Burrell H. R, Dokas L. A, and Springer A. D. (1978) Progress in biochemical approaches to learning and memory, in Psychopharmacology: A Generation of Progress (Lipton M. A., Demascio A., and Killam K. F., eds), pp. 623635. Raven Press, New York.

Davis R. E. and Agranoff B. W. (1966) Stages of memory formation in goldfish: evidence for an environmental trigger. Proc. Natl. Acad. Sci. USA 55, 555-559.

Dunn A. J. (1980) Neurochemistry of learning and memory: an evaluation of recent data. Annu. Rev. Psychol 31, 343-390.

Haglid K. G., Hydén H., and Lange P. W. (1975) Localization and response of the 14-3-2 brain protein. J. Neurosci. Res. 1, 3135.

Harper C. P. and Thoenen H. (1980) Nerve growth factor: biological significance, measurement, and distribution. J. Neurochem. 34, 5-16.

Hydén H. and Lange P. W. (1970a) Correlation of the S100 brain protein with behavior. Exp. Cell Res. 62, 125-132.
Hydén H. and Lange P. W. ( $1970 b)$ Brain-cell protein synthesis specifically related to learning. Proc. Natl. Acad. Sci. USA 65, 898904.

Krnjević K., Morris M. E., Reiffenstein R. J., and Ropert N. (1982) Depth distribution and mechanism of changes in extracellular $\mathrm{K}^{+}$and $\mathrm{Ca}^{2+}$ concentrations in the hippocampus. Can. J. Physiol. Pharmacol. 60, 1658-1671.

Majocha R. E., Schmidt R., and Shashoua V. E. (1982) Cultures of zona ependyma cells of goldfish brain: an immunological study of the synthesis and release of ependymins. J. Neurosci. Res. 8 , $331-342$.

Mileusnic R., Rose S. P. R., and Tillson P. (1980) Passive avoidance learning results in region-specific changes in concentrations of and incorporation into colchicine binding proteins in the chick brain, $J$. Neurochem. 34, 1007-1015.

Rönnback L. and Hydén H. (1980) Stimulation of a soluble protein fraction in the hippocampus of rats subjected to brief training. J. Neurol. Sci. 48, 179-183.

Rose S. P. R. (1981) What should a biochemistry of learning and memory be about? Neuroscience 6, 811-821.

Rosenzweig M. R. and Bennett E. L., eds (1976) Neural Mechanisms of Learning and Memory. M.I.T. Press, Cambridge, Massachusetts.

Schmidt R. (1985) Involvement and function of specific goldfish brain glycoproteins (ependymins) in two different learning paradigms. (Abstr) J. Neurochem. 44 (Suppl), 21.

Schmidt R. (1986) Biochemical participation of glycoproteins in memory consolidation after two different training paradigms in goldfish, in Advances in Bioscience. Vol. 59: Learning and Memory: Mechanisms of Information Storage in the Nervous System (Matthies H., ed), pp. 213-222. Pergamon, Oxford.

Schmidt R. and Lapp H. (1987a) Regional distribution of ependymins in goldfish brain measured by radioimmunoassay. Neurochem. Int. (in press).

Schmidt R. and Lapp H. (1987b) Subcellular distribution of ependymins in goldfish brain measured by radioimmunoassay. $J$. Neurochem. 48, 1862-1869.

Schmidt R. and Piront M.-L. (1985) Participation of specific glycoproteins in memory formation. Biol. Chem. Hoppe Seyler 336, 127.

Schmidt R. and Shashoua V. E. (1981) A radioimmunoassay for ependymins $\beta$ and $\gamma$ : two goldfish brain proteins involved in behavioral plasticity. J. Neurochem. 36, 1368-1377.

Schmidt R. and Shashoua V. E. (1983) Structural and metabolic relationships between goldfish brain glycoproteins participating in functional plasticity of the central nervous system. $J$. Neurochem. 40, 652-660.

Schmidt R., Löffler F., Müller H. W., and Seifert W. (1986) Immunological cross-reactivity of cultured rat hippocampal neurons with goldfish brain proteins synthesized during memory consolidation. Brain Res. 386, 245-257.

Shashoua V. E. (1968) RNA changes in goldfish brain during learning Nature 217, 238-240.

Shashoua V. E. (1973) Seasonal changes in the learning and activity patterns of goldfish. Science 181, 572-574.

Shashoua V. E. (1974) RNA metabolism in the brain. Int. Rev. Neurobiol. 16, 183-231.

Shashoua V.E. (1976) Brain metabolism and the acquisition of new behaviors. I. Evidence for specific changes in the pattern of protein synthesis. Brain Res. 111, 347-364.

Shashoua V.E. (1979) Brain metabolism and the acquisition of new behaviors. III. Evidence for secretion of two proteins into the brain extracellular fluid after training. Brain Res. 166, 349358.

Shashoua V. E. (1981) Extracellular fluid proteins of goldfish brain: studies of concentration and labeling patterns. Neurochem. Res. 6, 1129-1147.

Shashoua V. E. (1982) Molecular and cell biological aspects of learning: toward a theory of memory. Adv. Cell. Neurobiol. 3, $97-141$. 
Shashoua V. E. (1985) The role of brain extracellular proteins in neuroplasticity and learning, in Cellular and Molecular Neurobiology, Vol. 5: Activity-Dependent Synaptic Changes, pp. 183-207. Plenum Press, New York

Shashoua V. E. and Moore M. E. (1978) Effect of antisera to $\beta$ and $\gamma$ goldfish brain proteins on the retention of a newly acquired behavior. Brain Res. 148, 441-449.

Shashoua V. E. and Schmidt R. (1987) Learning and memory: neurochemical aspects, in Encyclopedia of Neuroscience (Adelman G., ed), in press. Birkhäuser, Boston.

Singer W. (1987) Activity-dependent self-organization of synaptic connections as a substrate of learning, in The Neural and Molecular Bases of Learning (Changeux J.-P. and Konishi M., eds), in press. Dahlem Konferenzen, John Wiley and Sons, Chichester.

Unsicker K. (1986) Differentiation and phenotypical conversion of adrenal medullary cells: the effects of neuronotrophic, neuritepromoting, hormonal, and neuronal signals, in Neurohisto- chemistry: Modern Methods and Applications (Panula P., Päivärinta H., and Soinila S., eds), pp. 183-206. Alan R. Liss, New York.

Varon S. and Adler R. (1981) Trophic and specifying factors directed to neuronal cells. Adv. Cell. Neurobiol. 2, 115-163.

von Holst E. (1970) Zur Verhaltensphysiologie bei Tieren und Menschen, Vol. 2, pp. 188-190. Piper, München.

Zomzely-Neurath C. and Keller A. (1977) The different forms of brain enolase: isolation, characterization, cell specificity and physiological significance, in Mechanisms, Regulation and Special Function of Protein Synthesis in the Brain (Roberts S. Lajtha A., and Gispen W. H., eds), pp. 279-298. Elsevier/ North Holland, Amsterdam.

Zomzely-Neurath C. E. and Walker W. A. (1980) Nervous systemspecific proteins: 14-3-2 protein, neuron-specific enolase and S-100 protein, in Proteins of the Nervous System, 2nd ed. (Bradshaw R. A. and Schneider D. M., eds), pp. 1-57. Raven Press, New York. 